\title{
Neglected infectious diseases: are push and pull incentive mechanisms suitable for promoting drug development research?
}

\author{
FRANK MUELLER-LANGER* \\ Max Planck Institute for Intellectual Property and Competition Law, International Max Planck Research School for \\ Competition and Innovation, Munich, Germany
}

\begin{abstract}
Infectious diseases are among the main causes of death and disability in developing countries, and they are a major reason for the health disparity between rich and poor countries. One of the reasons for this public health tragedy is a lack of lifesaving essential medicines, which either do not exist or badly need improvements. In this article, we analyse which of the push and pull mechanisms proposed in the recent literature may serve to promote research into neglected infectious diseases. A combination of push programmes that subsidise research inputs through direct funding and pull programmes that reward research output rather than research input may be the appropriate strategy to stimulate research into neglected diseases. On the one hand, early-stage (basic) research should be supported through push mechanisms, such as research grants or publicly financed research institutions. On the other hand, pull mechanisms, such as prize funds that link reward payments to the health impacts of effective medicines, have the potential to stimulate research into neglected diseases.
\end{abstract}

\section{Introduction}

Infectious diseases are a major reason for the health disparity between rich and poor countries (Stiglitz and Jayadev, 2010). They kill 14 million people worldwide every year, predominantly affecting members of poor populations in developing countries [World Health Organization (WHO), 2001]. In fact, these countries bear $98 \%$ of the global disease burden for infectious diseases, such as malaria, trachoma, lymphatic filariasis or schistosomiasis (WHO, 2008). Reasons for this public health tragedy can be understood as a combination of market failure with respect to drug development and public health policy failures. One strand of literature on the latter

\footnotetext{
*Correspondence to: Dr Frank Mueller-Langer, Max Planck Institute for Intellectual Property and Competition Law, Marstallplatz 1, D-80539 Munich, Germany. Email: frank.mueller-langer@ip.mpg.de

The online version of this article is published within an Open Access environment subject to the conditions of the Creative Commons Attribution-NonCommercial-ShareAlike licence $<\mathrm{http}$ //creativecommons.org/licenses/ by-nc-sa/3.0/>. The written permission of Cambridge University Press must be obtained for commercial re-use.
} 
topic suggests that international harmonisation of patent policies and drug safety regulations are potential obstacles to improving the health situation in developing countries (Kremer, 2001; Trouiller et al., 2001). Another strand of literature focuses on policy failures within developing countries. It identifies lacking education, weak legal frameworks or faulty allocation of medical staff as the fundamental challenges (WHO, 1996; Travis et al., 2004).

While addressing these issues may contribute to reducing the disease burden in poor countries, the focus of the present article lies on the analysis of the market failure of the drug development paradigm; lifesaving essential medicines either do not exist or badly need improvements to meet the developing countries' needs (Mrazek and Mossialos, 2003; Kremer and Williams, 2010). We adopt the neoliberal institutional setting as the basis for our analysis. The question of whether different policy approaches under other institutional arrangements are suitable to address this market failure is beyond the scope of this article. ${ }^{1}$ Under current market conditions, the pharmaceutical industry has little incentive to invest in research and development $(\mathrm{R} \& \mathrm{D})$ for infectious diseases that predominantly plague poor nations, as medicines cannot be sold there at a price that would allow pharmaceutical firms to cover their high R\&D costs (Buckup, 2008). There is a significant positive relationship between a pharmaceutical firm's expected returns and its R\&D expenditures (Grabowski and Vernon, 2000). Furthermore, Acemoglu and Linn (2004) suggest that pharmaceutical R\&D is directed towards more profitable markets. In fact, the pharmaceutical markets in the poorest countries are too small to trigger significant R\&D for medicines for neglected infectious diseases that are prevalent in these countries (Maurer, 2005). Although a large number of consumers in the developing world lack effective medicines for such diseases, their purchasing power is too low to generate a sufficiently large market (Kremer, 2002).

Under these circumstances, pharmaceutical companies decide that the return on $R \& D$ investment for neglected infectious diseases will be less than the return on an equivalent investment for medicines for the developed world (Webber and Kremer, 2001). ${ }^{2}$ Although the infectious diseases that are the most prevalent in poor nations account for $11.4 \%$ of the global disease burden, only $1 \%$ of all pharmaceutical products marketed in the period from 1975 to 1999 were targeted at them (Trouiller et al., 2002). The introduction of patent protection in the developing world is not a sufficient solution to the problem of underinvestment in R\&D for neglected diseases (Kremer, 2002). Even if patent protection provided an adequate incentive mechanism to successfully stimulate R\&D, patented

1 See Thorsteinsdóttir et al. (2004) for a discussion of Cuba's biotechnology health research system that, for instance, led to the development of the meningitis B vaccine in the 1980s. Another example is the strong biotechnology industry in China (Singer and Daar, 2001).

2 One may argue that local R\&D for medicines for neglected diseases prevalent in countries with emerging pharmaceutical industries, such as India or Brazil, may help to eradicate those diseases. However, Kettler and Modi (2001) find that Indian pharmaceutical companies are more likely to target diseases that are prevalent in industrialised countries, such as diabetes or cancer. 


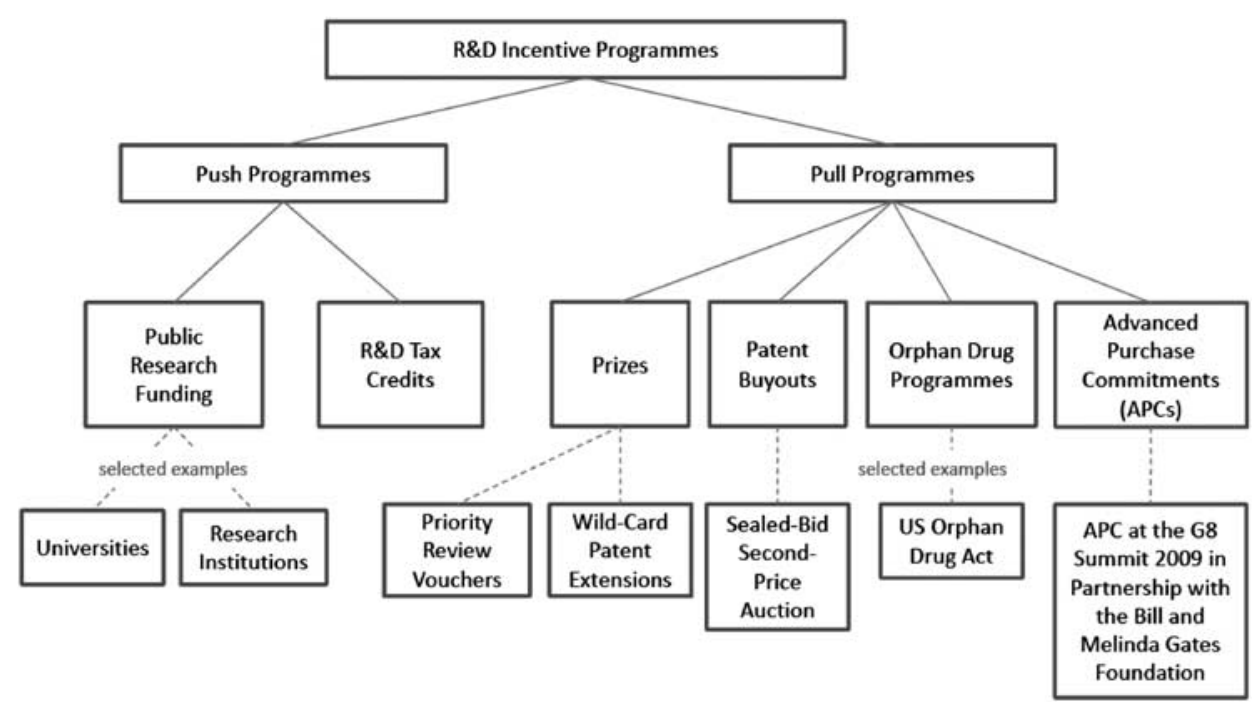

Figure 1. Push and pull R\&D incentive programmes and selected examples

medicines may still not be affordable for large groups of consumers in poor countries (Kremer and Glennerster, 2004).

In this article, we analyse which incentive mechanisms mitigate the problem of underinvestment in R\&D for medicines for neglected diseases. Figure 1 provides an overview of the push and pull programmes and selected examples as discussed in the article. While both types of programmes aim to increase the incentives to allocate resources into neglected disease research, they differ in their approaches. While push programmes such as R\&D tax credits aim to reach their goal by subsidising research inputs, pull mechanisms, such as prizes, patent buyouts or advanced purchase commitments (APCs) rather reward research output. We explain the different incentive mechanisms in detail and provide a discussion of related advantages and disadvantages for each alternative. In particular, we analyse the question of whether push programmes may provide the basis for subsequent applied research in the pharmaceutical industry by promoting basic (non-patentable) research. In addition, we analyse the conditions under which pull mechanisms may help to reduce market uncertainty and increase the expected market for targeted drugs or medicines for neglected diseases.

We selected the programmes under study on the basis of four criteria. First, we evaluated the academic relevance of each proposal in terms of quality and originality of the contribution. Second, we analysed the practical applicability of each proposal in the field. In particular, we addressed the question of whether pilot projects already exist that passed the market test. Third, and most importantly, we investigated the potential of each proposal to increase R\&D incentives for neglected diseases by comparing the advantages and shortcomings of each policy option. Therefore, the scientific level of the discussion on these 
advantages and shortcomings was an important (fourth) criterion for including a proposal in our analysis.

The following section analyses push programmes. The third section studies pull programmes. In the fourth section, we conclude and provide policy recommendations.

\section{Are push programmes suitable for promoting research into neglected diseases?}

Programmes that subsidise research inputs through direct funding, such as research grants to universities and government laboratories or tax credits for $\mathrm{R} \& \mathrm{D}$ investment, are called push programmes. Current push programmes aimed at promoting R\&D in malaria research are the Medicines for Malaria Venture and the Malaria Vaccine Initiative.

\subsection{Publicly funded research institutions}

Large publicly funded research institutions, such as universities or the US National Institutes of Health, play a significant role in promoting basic research (Glennerster and Kremer, 2001). They help to create non-patentable fundamental scientific knowledge, which provides a base for downstream discoveries of the profit-seeking pharmaceutical industry (Maurer, 2005). This publicly available fundamental scientific knowledge generated by publicly funded research institutions reduces the research costs incurred by the pharmaceutical industry. It thereby potentially increases private incentives to invest in applied research (Webber and Kremer, 2001). However, negative experiences with publicly funded programmes in financing the commercial R\&D of marketable pharmaceutical products suggest that push programmes are subject to difficulties resulting from information asymmetries between researchers and government research administrators (Kremer, 1998). Moral hazard problems may arise because government research administrators cannot perfectly monitor research activities (Kremer and Glennerster, 2004). Researchers, once they are funded, may have incentives to redirect their resources to non-core research activities, directing their efforts towards unrelated and more rewarding research projects or towards preparing the next grant application (Webber and Kremer, 2001). The effective management of the performance of researchers, together with reputation effects and the contingency of future funding on previous performance, may help to mitigate moral hazard problems (Gallini and Scotchmer, 2002).

Adverse selection problems may occur in publicly funded push programmes. Difficulties in determining the quality of research are likely to arise because these programmes pay for research inputs on the basis of an ex ante evaluation of potential product delivery, not on the basis of successful product development (Maurer, 2005). Researchers have better information about the probability of 
success of a research programme than do government research administrators (Kremer and Glennerster, 2004). They may, therefore, have incentives to act opportunistically by overestimating the probability of success of the research programme in order to acquire the funding in the first place or to increase the amount awarded (Hollis, 2007). However, due to the lack of appropriate information, government research administrators may be unable to determine which research projects should be funded or which diseases should be targeted (Kremer, 2002). Hence, asymmetric information with respect to the probability of success of research projects may result in the funding of projects that only have a small probability of success (Kremer and Glennerster, 2004). Even worse, government research administrators may decide not to fund a worthwhile research project with a high probability of success because they doubt that the project's probability of success is credible (Kremer, 2002). These problems can be diminished if a private pharmaceutical firm or research institution is only paid by a government agency after it has successfully developed a specific marketable pharmaceutical product. In this case, researchers will have strong incentives to evaluate the likelihood of success of their research projects more realistically and to focus on the development of the desired product (Kremer and Glennerster, 2004).

In addition to the publicly funded research institutions mentioned above, a number of product development partnerships (PDPs) have emerged in recent years. PDPs are long-term collaborations between partners from academia, the public sector and pharmaceutical companies that target the development of new medicines. Table 1 provides an overview of selected major PDPs with a special focus on the development of vaccines and medicines for neglected diseases.

\subsection{Targeted R\&D tax credits}

In contrast to publicly funded research institutions, targeted R\&D tax credits are a direct contribution to pharmaceutical companies, designed to promote $R \& D$ in specific neglected diseases (Hall and van Reenen, 2000). R\&D tax credits finance research inputs rather than research outputs (Kremer and Glennerster, 2004). In the United States of America, for instance, pharmaceutical companies are eligible for a $20 \% \mathrm{R} \& \mathrm{D}$ tax credit. If a neglected disease also qualifies as an orphan disease, for example, due to its low disease prevalence in the United States, as is the case with malaria or tuberculosis (Grabowski, 2005), a tax credit of as high as $50 \%$ on clinical development costs is possible. The US Orphan Drug Act, which addresses these issues will be further explained in Section 3 of this article. The private returns to $R \& D$ for neglected diseases are much lower than the social returns to R\&D for these diseases (Lybecker and Freeman, 2007). Under these conditions, private firms choose a socially sub-optimal level of R\&D investment. R\&D tax credits address this problem. However, as targeted R\&D tax credits subsidise research inputs for a specific pharmaceutical product rather than rewarding successful product 
Table 1. Selected examples of product development partnerships

\begin{tabular}{|c|c|c|}
\hline Name (acronym) & Targeted diseases & $\begin{array}{l}\text { Total } \\
\text { expenditure } \\
2010 \text { in USD }\end{array}$ \\
\hline Aeras & Tuberculosis & 51.6 million \\
\hline $\begin{array}{l}\text { Contraceptive Research and } \\
\text { Development Programme } \\
\text { (CONRAD) }\end{array}$ & HIV/AIDS & $\mathrm{n} / \mathrm{a}$ \\
\hline Dengue Vaccine Initiative (DVI) & Dengue & $\mathrm{n} / \mathrm{a}$ \\
\hline $\begin{array}{l}\text { Drugs for Neglected Diseases } \\
\text { Initiative (DNDi) }\end{array}$ & $\begin{array}{l}\text { Chagas disease, helminth infections, human } \\
\text { African trypanosomiasis, leishmaniasis, } \\
\text { malaria, paediatric HIV }\end{array}$ & 30.9 million" \\
\hline European Vaccine Initiative (EVI) & $\begin{array}{l}\text { Chagas disease, dengue, HIV/AIDS, } \\
\text { leishmaniasis, malaria, tuberculosis }\end{array}$ & 15.7 million" \\
\hline $\begin{array}{l}\text { Foundation for Innovative New } \\
\text { Diagnostics (FIND) }\end{array}$ & $\begin{array}{l}\text { Human African trypanosomiasis, } \\
\text { leishmaniasis, malaria, tuberculosis }\end{array}$ & 25.7 million \\
\hline $\begin{array}{l}\text { Global Alliance for Vaccines and } \\
\text { Immunisation (GAVI) }\end{array}$ & $\begin{array}{l}\text { Pneumococcal disease, haemophilus } \\
\text { influenzae type b, yellow fever, hepatitis B, } \\
\text { diphtheria, tetanus, pertussis }\end{array}$ & 899.0 million \\
\hline $\begin{array}{l}\text { Infectious Disease Research } \\
\text { Institute (IDRI) }\end{array}$ & $\begin{array}{l}\text { Chagas disease, leishmaniasis, leprosy, } \\
\text { malaria, pandemic influenza, tuberculosis }\end{array}$ & $\mathrm{n} / \mathrm{a}$ \\
\hline $\begin{array}{l}\text { Medicines for Malaria Venture } \\
\text { (MMV) }\end{array}$ & Malaria & 55.3 million \\
\hline TB Alliance & Tuberculosis & 46.3 million \\
\hline $\begin{array}{l}\text { Institute for One World Health } \\
\text { (IOWH) }\end{array}$ & $\begin{array}{l}\text { Diarrheal diseases, malaria, soil-transmitted } \\
\text { helminthiasis, visceral leishmaniasis }\end{array}$ & 17.8 million \\
\hline $\begin{array}{l}\text { International AIDS Vaccine } \\
\text { Initiative (IAVI) }\end{array}$ & HIV/AIDS & 88.0 million \\
\hline
\end{tabular}

AIDS $=$ acquired immunodeficiency syndrome; HIV $=$ human immunodeficiency virus. Source: Annual reports and official internet sites of the selected PDPs; Buckup (2008).

Note: Amounts marked by * were converted from EUR to USD using the purchasing power parity rate as of 31 December 2010.

development, they are subject to monitoring problems similar to those for other push mechanisms (Kremer, 2001). Pharmaceutical companies may have incentives to use their superior knowledge relative to government agencies to maximise their claims through creative accounting (Kremer and Glennerster, 2004).

As for R\&D for medicines for neglected diseases, for example, a malaria vaccine suitable for consumers in poor regions, $R \& D$ tax credits may present a number of issues (Mrazek and Mossialos, 2003). A targeted R\&D tax credit could be claimed by a pharmaceutical company pursuing R\&D for versions of the pharmaceutical product that are not appropriate for poor countries (Kremer and Glennerster, 2004). Suppose that a pharmaceutical company claims a targeted tax credit for R\&D for a malaria vaccine. The health needs of residents in low-income countries with respect to a malaria vaccine significantly differ from the health 
needs of residents in high-income countries: a malaria vaccine appropriate for travellers or military personnel, who only spend a limited period of time in an endemic region, may have different characteristics than a malaria vaccine appropriate for residents, who live in those regions permanently (Kremer, 2002).

There is one final drawback associated with targeted R\&D tax credits. They cannot mitigate the problem that residents in poor regions do not have access to affordable medicines (Kremer and Glennerster, 2004).

\subsection{Conclusion to push programmes}

Given the dearth of R\&D for medicines for neglected infectious diseases, direct public funding of basic research into these diseases could be an appropriate option to provide a base for downstream discoveries in the pharmaceutical sector. Moral hazard and adverse selection problems suggest that push programmes may not be the optimal solution to finance the development of marketable pharmaceutical products. Push programmes are, however, suitable to promote basic research and provide a basis for subsequent applied and commercially exploitable research. Additional mechanisms are necessary to encourage private pharmaceutical companies to develop medicines for neglected infectious diseases and to improve affordable access to those medicines for residents of low-income countries.

\section{Are pull programmes suitable for promoting research into neglected diseases?}

In contrast to push programmes, pull programmes such as prizes, APCs and patent buyouts reward research output rather than research input.

\subsection{Prizes}

A targeted prize is a payment that is made to a researcher conditional on the achievement of a particular outcome, that is, a technical specification of a desired drug or vaccine (Maurer, 2005). Non-profit organisations have recently identified prize challenges as tools to create incentives that foster R\&D in the pharmaceutical field. For instance, Prize4Life set up two challenges to promote R\&D on amyotrophic lateral sclerosis (ALS, also known as Lou Gehrig's disease). With respect to neglected infectious diseases, the X Prize Foundation and the Bill \& Melinda Gates Foundation are currently developing an X Prize Challenge for the effective diagnosis of tuberculosis in the developing world, where the world's second most lethal infectious disease is most prevalent.

Love and Hubbard (2007) promote a radical rethinking in the field of pharmaceutical innovation policy, suggesting a mandatory prize mechanism as an alternative to the marketing monopolies constituted by patents. The basic idea of the 'Medical Innovation Prize Fund' is to "divorce the incentive for innovation from the product's price to consumers" so that "knowledge goods, including 
the R\&D for a new medicine, can be placed in the public domain immediately" (Love and Hubbard, 2007: 1528). The reward shall only be given if an innovation has made a significant impact on public health. This would lead to 'open' innovations, yet still reward innovators financially (provided that patients benefit from the new drug). An example of such a mechanism is the prize fund introduced by former US Representative B. Sanders, called the Medical Innovation Prize Act, based on proposals by Love and Hubbard. ${ }^{3}$ The total size of the proposed fund was to be $0.5 \%$ of the US gross domestic product. The prize fund would have been structured to target diseases that predominantly affect poor nations, with a minimum initial allocation of $4 \%$ for globally neglected diseases.

Hollis and Pogge (2008) promote a voluntary prize fund named the 'Health Impact Fund' (HIF), which is designed as a supplement to the existing system of patent protection. In this optional pay-for-performance scheme for new medicines, pharmaceutical companies would be free to abandon monopoly pricing (but not their exclusivity right deriving from a patent) and instead participate by registering products with the HIF, which would reward them in proportion to the measurable net health impacts of their products. Rewards would be conditional on the products being priced (roughly) no higher than the average cost of production (Pogge, 2010). The scope of the HIF would be global. Participating states would act as funding partners.

As for the nature of the payment, there are two design options. The first option is a fixed pool to be split among the innovators according to the product's health impact; the pool might be guaranteed for, say, 15 years. This would make the cost of the HIF politically attractive and predictable for member states, but it would also place a burden on innovators resulting from uncertainty as to the exact rate of reward per quality-adjusted life year (QALY). ${ }^{4}$ An alternative would be to offer innovators a fixed amount of money per QALY. This would remove uncertainty for innovators but impose uncertainty on member states regarding the annual cost of the HIF (Pogge, 2010). Unlike the mandatory prize fund proposed by Love and Hubbard, the voluntary HIF would be targeted at medicines for neglected infectious diseases in particular, while innovations with very high market value would still be distributed under the patent system (Hollis and Pogge, 2008).

Other important prize schemes discussed in the literature are priority review vouchers and wild-card patent extensions. Regarding the former, Ridley et al. (2006) propose to grant pharmaceutical companies that successfully develop therapies for neglected diseases transferable priority review vouchers. To be eligible for a voucher, therapies must meet particular criteria such as approval by the Food and Drug Administration (FDA) or the European Medicines Agency (EMA) and,

3 Medical Innovation Prize Act (United States). H.R. 417. 109th Congress, 1st Session, 26 January 2005. An identical bill was reintroduced in 2007. Note that it never became law.

4 In this standardised measure of health benefit, a year in perfect health has the value of one, while a year in poorer health has a value between zero and one. 
among other things, clinical superiority to existing therapies. The priority review voucher entitles its holder to the faster priority review process of the FDA for another drug under development. The additional resources required for the priority review process of the FDA would be recovered through an extra user fee to the voucher holder. Ridley et al. (2006) estimate a reduction in review time from an average of 18 to 6 months. This would increase the net present value of sales by more than $\$ 300$ million if the priority review voucher is used for a blockbuster medication. Most notably, the priority review voucher scheme was enacted in the United States in 2007.

A similar scheme discussed in the literature is the wild-card patent extension programme (Spellberg et al., 2007; Sonderholm, 2009). It rewards the development of a critically needed targeted drug of a particular pharmaceutical company by extending the patent on another marketed drug within the portfolio of the company. The patent extension of between six months and two years could also be sold to other companies. The tradability of patent extensions and priority review vouchers ensures that even (small) companies that do not have any highrevenue medication under patent or under development have an incentive to direct $R \& D$ resources into neglected disease research.

\subsubsection{Advantages of prizes}

First, suppose that the creation of a new drug or vaccine is successfully stimulated through a prize and donated to the public or made available to the public at the cost of production. In this case, the drug or vaccine is not subject to the inefficient (monopoly) pricing associated with the market exclusivity provided by a patent. Second, in contrast to push programmes, prizes are not likely to be subject to moral hazard problems. Because a researcher will only receive the prize once the desired drug or vaccine is successfully developed, incentives to stray from the task or shift research priorities to other projects are lower under a prize mechanism (Maurer, 2005). Third, the technical specification of a prize could be designed to spur the development of a drug or vaccine appropriate for use in low-income countries (Kremer and Glennerster, 2004). For instance, the prize for the development of a malaria vaccine may only be awarded if it fulfils specific requirements, for example, that the vaccine should prevent not less than $50 \%$ of plasmodium falciparum malaria, which is the most dangerous type of malaria with the highest mortality rate (Maurer, 2005; WHO, 2005). Fourth, in contrast to patents, an innovator awarded a monetary prize for successfully developing a specific drug does not have to fear profit-reducing infringement. He does not incur the high costs of litigation and identifying alleged patent infringers (Gallini and Scotchmer, 2002). With prize funds such as the HIF or the Medical Innovation Prize Fund there are further advantages. Because rewards would be linked to actual results in terms of incremental healthcare benefits, the pharmaceutical industry would not be inclined to manufacture inferior or unnecessary products but would have incentives to make a measurable impact 
on global health. Consequently, this would create competition for product quality and effectiveness (Love and Hubbard, 2007). However, prices would remain low because pharmaceutical companies would have a great interest in making their product available to the greatest number of people in order to achieve the greatest possible health impact (Pogge, 2010). Additionally, companies registered with a particular fund would have an incentive to do more than just sell the product. For their products to make an optimal impact on public health, patients would need to be fully instructed on dosage and compliance. Because of the lack of a public health infrastructure in poor countries, patients often receive unsuitable products or suitable products that are not used in the right way (Mrazek and Mossialos, 2003). This 'last-mile problem' would be mitigated in a prize system in which companies would have an incentive to ensure that products are used properly by cooperating with governments and non-governmental organisations (Pogge, 2010).

Finally, the advantages of the FDA priority review voucher scheme are its relatively low cost to the public and higher R\&D incentives for medicines for neglected diseases (Ridley et al., 2006). If the market for transferable vouchers functions efficiently, the priority review will always be used for those drugs that are valued most by the public, as those will have the highest expected return for the drug company. Thus, priority review vouchers do not only increase R\&D incentives for medicines for neglected diseases, but also help to make demanded (blockbuster) drugs available to the public sooner.

\subsubsection{Disadvantages of prizes}

First, if the sponsor of a prize does not have accurate information about the prospective benefits and costs of the innovation to be rewarded, the reward is likely to differ from the social value of the innovation, resulting in either underpayment or overpayment (Maurer, 2005). The core difficulty with respect to prizes is determining how large the prize should be. For instance, the HIF only rewards manufacturers of products that have made a positive impact on public health. Calculating the incremental health impact of medicines, which is essential for the effective operation of the HIF, appears to be an extremely challenging task that could very well overburden agencies. Clinical trials do not give conclusive and accurate assessments of a drug's impact and are usually complicated by factors such as varying effects across different populations or the lack of suitable biomarkers (Liddell, 2010). Although these efforts could be supplemented by field trials, the huge expenditures of time and money demanded by such undertakings could easily prevent agencies from carrying them out in the first place (Liddell, 2010). Because the assessment of health impacts would rely in part on the number of units sold, fraud, aggressive marketing and advertising could become common practices among companies to exaggerate the benefits of their products (Liddell, 2010). As incremental health benefits are difficult to calculate, even ex post, decision makers could act at their own discretion. For instance, a new drug typically substitutes or complements an existing product. The new drug may also 
be (more) beneficial to certain patients and not beneficial to others (Kremer and Williams, 2010). Depending on the room for discretion left to a committee in charge of ex post assessment, prize funds may create the potential for static costs associated with rent-seeking and dynamic losses from inappropriate incentives (Kremer and Williams, 2010). A further problem with the assessment of new products arises if one considers complementary inventions. The exact distribution of the awards may be difficult because producers would have incentives to overstate the importance and the R\&D costs of their respective inventions and thus mislead decision makers about the size of their share (Kremer and Williams, 2010). Additionally, sponsors have incentives to renege on their promise once the invention is finished, for example, by creating reasons that the invention is useless and not eligible for the prize (Maurer, 2005). It is, therefore, of critical importance that the rules of a prize, for example, the process for assessing the value of an innovation, are clearly specified in advance and enforceable by a court (Kremer and Glennerster, 2004). The sponsor must adopt a credible commitment strategy ex ante to reduce his ability to renege ex post to prevent the erosion of the incentives to innovate. This time-inconsistency problem may also be solved through a bonding mechanism, that is, a conflict resolution mechanism.

Second, Maurer (2005) suggests that publicly funded prizes are likely to be less favourable politically than patents because large lump sum (governmental) prize payments are more visible to voters than patent revenues spread out over a large number of doses.

Third, shortages in supply may arise under programmes that condition the participation on drugs being marketed at or below a certain price cap (e.g. average cost pricing under the HIF). Under rigid price systems, prices cannot adjust to short-term market shifts such as demand fluctuations or supply problems at the manufacturing facilities. For instance, the Medicare Part B programme in the US caps the reimbursement of physicians for medications used in their practices at the average sales prices of the last six months plus $6 \%$. In fact, short-term shortages, especially for cancer drugs, occurred under this payment system as it made it difficult for the manufacturers to increase their prices by more than $6 \%$. At higher prices, physicians would make a loss selling those medications. FDA (2011) reports 178 drug shortages, at least some of which were due to rigid price systems (Link et al., 2012). This development suggests that immediate and constant provision of generic drugs at average cost pricing cannot be taken for granted. Additional profit inducements may be necessary.

Fourth, prizes may result in a wasteful prize race in which R\&D investments are duplicated (Kremer and Glennerster, 2004). If prizes offer the full social value of an innovation, competing firms may allocate excessive resources to their research. Another disadvantage of prizes compared with patents stems from the fact that public or private sponsors are required to finance the prize (Maurer, 2005). If a prize is publicly financed, it may eliminate the deadweight loss associated with patents. However, public financing (i.e. through taxation of other goods) creates its own 
welfare-reducing distortions. Furthermore, if one considers a mandatory prize fund for the entire pharmaceutical market, it may be hazardous to make pharmaceutical $\mathrm{R} \& \mathrm{D}$ depend on the willingness of states to pay into the system, as unforeseen circumstances may cause them to commit to lower amounts of funding or prevent them from participating in the first place (Hollis and Pogge, 2008). Conversely, there is a certain danger that companies will simply ignore any voluntary mechanism if it generates lower profits than monopoly pricing. If, however, rewards from funds such as the HIF were great enough to increase existing profit margins in the pharmaceutical sector at the expense of the public purse, this aspect of public funding would arguably not be appealing to taxpayers (Liddell, 2010).

Finally, prize schemes such as the FDA priority review vouchers or wild-card patent extensions do not set an explicit incentive for the developer to ensure consumer access to affordable medicines in low-income countries (Ridley et al., 2006). In contrast to monetary prizes such as the HIF that can be granted conditional on actual health impact in terms of QALYs, priority review vouchers, once rewarded, give no additional incentive to make sure that patients have access to the newly developed drug. Another disadvantage of the voucher scheme may be that the FDA approval for the drug for which the voucher is used is subject to uncertainty, which reduces the expected value of the voucher.

\subsection{Patent buyouts}

Kremer (1998) examines the potential of patent buyouts to promote innovations and analyses the use of auctions to determine patent buyout prices. He suggests that the patent authority should offer to buy relevant patents at a price that is equal to their estimated private value plus a mark-up reflecting the ratio of the social to the private value of the invention. Under the assumption that the value of an invention is observable to competitors of the patent-holding firm, the market value of the patent would be estimated through a sealed-bid second-price auction. The patent authority should place most of the patents it buys in the public domain so that the innovation can be produced and marketed at a competitive price. However, only a small fraction of the patents purchased would be sold to the firm with the highest bid to provide the auction participants with incentives to disclose their true expectations of the market value of the patent (Kremer, 1998; Harhoff et al., 2003). The patent authority would randomly choose which patent will eventually be sold to the high bidder and thus not be placed in the public domain.

\subsubsection{Advantages of patent buyouts}

First, because the price the original developer of a patented innovation can realise from selling the patent to the patent authority typically exceeds the private value of the patent, patent buyouts are likely to increase private R\&D incentives (Kremer, 1998). Thus, they may help to moderate the market failure 
that private returns on $R \& D$ are typically lower than social returns on $R \& D$ (Kremer and Glennerster, 2004).

Second, as most of the patents purchased will enter the public domain so that the innovation can be produced and marketed at a competitive price, the deadweight losses due to inefficient monopoly pricing associated with patents will be eliminated. Kremer (1998) points out that the pharmaceutical sector would be a natural area in which to try the buyout scheme. When purchased patents are put in the public domain, pharmaceutical markets are likely to be relatively competitive, as compared with a patent-induced monopoly situation with large monopoly mark-ups. Moreover, considerable information about medical products is gathered during the patent approval procedure of a new medicine, for example, through the EMA in the European Union or the FDA in the United States. Auction participants could therefore use this information to make informed bids (Kremer, 1998). Finally, monopoly profits would be eliminated in those cases in which the patent purchased is put in the public domain. Patent buyouts thus potentially mitigate the problem that the original innovator's competitors are typically inclined to invest in wasteful duplicative research for substitute products in order to capture profits from the innovator (Kremer, 1998).

\subsubsection{Disadvantages of patent buyouts}

The second-price auction, which is of crucial importance to the effective operation of patent buyouts, is potentially vulnerable to collusive behaviour between the patent holder and auction participants (Kremer, 1998). Patent holders have incentives to pay auction participants to make a bid that is higher than their true valuation of the patent to increase buyout prices (Kremer, 2001). Most of the purchased patents are placed in the public domain, whereas only a small fraction of them would actually be sold to the highest bidders. Hence, on the one hand, the bribed bidders would face a low probability of having to pay the patent authority. On the other hand, the patent holders would be confident of getting an inflated price. However, Kremer (1998) points out several mechanisms for preventing collusive behaviour, for example, sealed bids, punishing colluding firms, or rewards for whistleblowers, among others.

Second, patent buyouts could aggravate the problem of patent races and wasteful duplication of R\&D expenses, as the price the patent authority would pay for a patent is typically higher than its private (commercial) value (Gallini and Scotchmer, 2002). Additionally, patent buyouts are a visible lump sum payment and thus are likely to be less politically attractive than the less visible patent revenues spread out over a large number of doses (Maurer, 2005).

\subsection{Orphan drugs}

Huntington's disease, ALS and Tourette syndrome are referred to as rare diseases or conditions, as only a very small number of people suffer from them. 
Under normal market conditions, the prospective market for medicines for these rare diseases is too small to stimulate research by the private pharmaceutical sector (Villa et al., 2009). Drugs to cure these rare diseases are commonly referred to as 'orphan drugs'. Unlike neglected infectious diseases, these diseases are not necessarily diseases of poverty; however, they share the same core problem. Under normal market conditions, the pharmaceutical sector would be reluctant to develop new medicines to treat and cure these diseases. The main difference is that additional incentive programmes to stimulate research into rare diseases have already been successfully established in industrialised countries. ${ }^{5}$ The US Orphan Drug Act provides R\&D incentives in the form of regulatory assistance, for example, fast-track regulatory approval, research grants and tax credits for clinical testing and R\&D expenses incurred in connection with research into diseases that affect fewer than 200,000 persons in the United States (Kremer and Glennerster, 2004).

In addition, seven-year market exclusivity, from the date of approval, is granted independent from already existing patent protection. ${ }^{6}$ The exclusivity is achieved by prohibiting a regulatory agency from granting marketing authorisation to the same medication made by another manufacturer to be used in the same therapeutic area (Villa et al., 2009). Especially with regard to drugs for which patent protection is not available, weak, subject to uncertainty or already expired, the exclusivity can be an important feature of the Orphan Drug Act (Shulman and Manocchia, 1997; Grabowski, 2005). While authorisation can still be granted to the same medication for another indication, the provision rules out direct competition from lower-priced generic versions of the same drug for the same indication during the exclusivity period (Rogoyski, 2006).

Empirical evidence suggests that the combination of push mechanisms, such as grants or tax benefits, and pull mechanisms, such as the promise of market exclusivity as provided by the Orphan Drug Act, successfully stimulates the development of medicines for rare diseases (Lichtenberg and Waldfogel, 2003). As of 4 October 2007, the total number of orphan drugs approved since 1983 is 315 (Ricklin and Lambris, 2007). In contrast, fewer than 10 such medicinal products for rare diseases were marketed in the decade prior to the Orphan Drug Act (Berndt et al., 2007). As to the underinvestment in R\&D for neglected infectious diseases, the Orphan Drug Act may serve as a successful and tested model of a combination of push incentives such as tax credits and grants and pull incentives such as the promise of market exclusivity over a certain period (Lichtenberg and Waldfogel, 2003).

5 The US Orphan Drug Act became effective in 1983. Japan and Australia established orphan drug systems based on the US model in 1993 and 1998, respectively. The European Regulation on Orphan Medicinal Products was approved by the European Parliament in 1999.

6 Section 527 of the Orphan Drug Act, 21 U.S.C. 360cc(a). See also Kremer and Glennerster (2004). 


\subsection{APCs}

APCs are ex ante commitments by national governments, international organisations or private foundations to purchase a certain quantity of a drug or vaccine that has yet to be invented at a certain price (Kremer and Glennerster, 2000). A government, for instance, could sign a contract to buy a prospective malaria vaccine suitable for use in low-income countries from a pharmaceutical company. The vaccine would be required to meet certain technical criteria such as safety, efficacy and usability and pass a market test regarding its suitability for use in low-income recipient countries (Kremer and Glennerster, 2000; Kremer, 2001). If the vaccine is successfully invented, the government would then make the vaccine available to countries in need at a price that is lower than the monopoly price (Kremer and Glennerster, 2004). The main purpose of an APC is to create a sufficiently large expected market for medicines for neglected infectious diseases so that pharmaceutical companies find an investment in R\&D worthwhile. Berndt et al. (2007) have investigated how large a purchase commitment would need to be to give developers incentives comparable to product markets for diseases prevalent in rich countries. Their results suggest that a $\$ 3.1$ billion commitment in the net present value of sales would be comparable to the value of the sales earned by an average of a sample of recently launched commercial products.

The first APC was launched at the G8 summit in L'Aquila, Italy, in 2009, when the governments of Italy, the United Kingdom, Russia, Norway and Canada announced a partnership with the Bill and Melinda Gates Foundation to commit $\$ 1.5$ billion to purchase pneumococcal disease vaccines tailored for developing countries. Per year, pneumococcal diseases kill more than 1.6 million people with more than $90 \%$ of these deaths occurring in the developing world. Pharmaceutical companies that take part in the programme have to guarantee in advance to provide a certain number of doses of vaccines for a 10 -year period at a price no higher than $\$ 3.50$ per dose. For the first $20 \%$ of their supplied doses, they will receive another $\$ 3.50$ per dose from the APC in order to incentivise the initial investment that is necessary to build up the required capacity. Of the $\$ 3.50$ that can be charged by the supplier, developing country governments only have to contribute a small co-payment. The larger share will be covered by the programme. The Bill and Melinda Gates Foundation estimates that this will bring pneumococcal vaccines to developing countries 10 years earlier than otherwise predicted, and therefore save over seven million lives by 2030. A transfer of the concept to fight other diseases like malaria, tuberculosis and AIDS, if the pilot APC succeeds, has already been announced by the Bill and Melinda Gates Foundation.

\subsubsection{Advantages of APCs}

First, the most attractive features of a suitably designed APC are arguably that it reduces market uncertainty and increases the expected market for a desired drug 
or vaccine, as it specifies a guaranteed price and the quantity to be purchased in advance (Webber and Kremer, 2001).

Second, in contrast to push mechanisms, APCs reward successful research output rather than research input (Kremer and Glennerster, 2004). They are consequently less vulnerable to moral hazard problems than push programmes.

Third, Kremer and Glennerster (2004) suppose that prospective sponsors are less than totally confident about the scientific prospects for the successful development of a malaria vaccine due to huge scientific challenges. On the one hand, a sponsor may not be inclined to provide direct push support to finance research into a malaria vaccine because she may not be willing to bear the risk of financing a project that will eventually fail. On the other hand, she might be more willing to make an APC, even when scientific prospects for success are not entirely clear (Kremer and Glennerster, 2004).

Nevertheless, pharmaceutical companies supposedly have better information than sponsors or buyers about the feasibility of scientific research. Hence, under an APC, those pharmaceutical companies that find that the development of a malaria vaccine is scientifically feasible and commercially attractive will pursue research into the vaccine (Kremer and Glennerster, 2004). By creating incentives for pharmaceutical companies to follow those research strategies that they think will result in marketable pharmaceutical products, APCs imitate the R\&D incentives a market typically provides (Webber and Kremer, 2001).

Fourth, suppose that the buyer of a vaccine or drug promoted through an APC makes the medicines available to consumers in least-developed countries either for free or at a relatively low price. In this case, APCs would help to mitigate both of the central problems related to neglected infectious diseases: the underinvestment in R\&D in those diseases and the lack of access to affordable drugs and vaccines in least-developed countries (Kremer, 2002).

Fifth, an analysis of the costs and effectiveness of APCs conducted by Berndt et al. (2007) revealed that APCs can have a substantial stimulating effect on the $\mathrm{R} \& \mathrm{D}$ for a specific vaccine and still be cost-effective.

\subsubsection{Disadvantages of APCs}

APCs are, like prizes, subject to a time-inconsistency problem (Kremer and Glennerster, 2004). Prior to the development of a desired drug or vaccine, buyers, such as governments or private foundations, have incentives to promise a guaranteed price that allows the innovating firm to cover its R\&D costs at a given specified quantity. Innovators, however, remain in a position of considerable economic dependence because they have made large investments relying upon the purchase commitment of (typically) a single party on the demand side. In this situation, buyers can make use of a vast bargaining power. They have incentives to renege on their promise ex post when the R\&D investment is sunk so as to obtain the drug or vaccine at the lowest possible price (Webber and Kremer, 2001). Potential innovators will anticipate this situation 
and be reluctant to invest in risky and expensive R\&D in the first place, or they may charge a premium before they take part in this type of pull programme (Maurer, 2005). Consequently, to prevent a hold-up situation, an explicit long-term commitment with clear, judicially enforceable rules is of crucial importance. One way to address this is to establish an adjudication committee independent of the sponsor or buyer (Kremer, 2002). The main purpose of this committee would be to evaluate whether a vaccine or drug promoted through a purchase commitment satisfies the eligibility requirements (Kremer and Glennerster, 2004).

Another disadvantage of APCs stems from the fact that sponsors must specify the desired innovation to be promoted through the purchase commitment beforehand (Villa et al., 2009). APCs may therefore be an inappropriate mechanism to promote basic research, as it is typically difficult to specify the output of basic research and appropriate eligibility requirements in advance (Kremer and Glennerster, 2004). In contrast to basic research, it is easier to specify what is meant by an efficacious and safe drug or vaccine. Institutions such as the EMA or the FDA are already specialised in making such specifications (Kremer and Glennerster, 2004). In addition, similar to the problem of setting an adequate reward for prizes, it may be difficult to set an adequate guaranteed purchasing price in advance to spur research because expected R\&D expenses are variable and difficult to estimate (DiMasi et al., 2003). Thus, Maurer (2005) suggests that APCs could result in either underpayment or overpayment. On the one hand, given a certain quantity, if the buyer sets the guaranteed price too low, the APC fails to stimulate R\&D. On the other hand, if the buyer sets the price for a certain quantity too high, the additional benefit may cause a sub-optimally high level of research efforts by competing firms.

Finally, like patent buyouts and prizes, APCs might be less politically attractive than patents because revenues spread out over a large number of doses are less noticed by voters than (government) payments (Maurer, 2005).

\subsection{Conclusion to pull programmes}

The core benefit of pull programmes is that the sponsors of the programme only have to pay when an innovation is successfully developed (Kremer and Glennerster, 2004). By linking payments to successful development, pull programmes decrease shirking by researchers and increase their incentives to concentrate their research efforts on marketable innovations (Kremer, 2002). The US Orphan Drug Act provides a tested benchmark of how research into diseases with a small expected market can be stimulated successfully through a combination of push and pull mechanisms. As for neglected infectious diseases, pull programmes such as the advanced vaccine purchase commitment brought forward by Kremer and Glennerster (2000) have the potential to increase the incentives for pharmaceutical companies to develop medicines for neglected diseases through a market-oriented and transparent approach. The main difficulty 
with targeted prizes is the advance specification of the desired innovation (Glennerster and Kremer, 2001). However, prizes are less vulnerable to moral hazard and adverse selection problems than push mechanisms and therefore appear to be an appropriate incentive mechanism to promote basic research where monitoring is typically difficult. Prize fund mechanisms such as the HIF appear to be adequate to promote research into neglected infectious diseases, as they link reward payments to both the successful development of effective medicines and the incremental health impact of registered medicines (Hollis and Pogge, 2008). Registered pharmaceutical companies would have significant interest in selling effective medicines at low prices and mitigating the 'last-mile problem'.

Nonetheless, patent buyouts also work in cases where the desired innovation cannot be specified in advance (Kremer, 1998). APCs and patent buyouts are market-based and link payments to the successful development of a desired product. An important feature of both is the potential for the establishment of access to affordable medicines in low-income countries (Kremer and Glennerster, 2004). Patent holders are likely to benefit from participating in the buyout mechanism, as they would enjoy a price that is typically significantly higher than the private value of the patent. Buyers of vaccines or drugs for neglected infectious diseases promoted through an APC would typically make the medicines available to patients in least developed countries either for free or for a low co-payment (Kremer and Glennerster, 2004). Nevertheless, it is of crucial importance that the advanced commitment is legally binding and enforceable to mitigate the hold-up problem once the innovation is made (Hollis, 2007). ${ }^{7}$ As for patent buyouts, the auction mechanism used to determine the buyout price in a buyout scheme must be safeguarded against collusive behaviour between auction participants and the patent holder (Kremer, 1998).

However, there are also some practical differences between APCs and patent buyouts. First, APCs only work if the sponsor determines specific details of the desired innovation beforehand, whereas the buyout scheme requires no such determination (Kremer, 2002). Second, APCs are less vulnerable to problems associated with the discovery of harmful side effects after the development and regulatory approval of a medicinal product (Kremer and Glennerster, 2004). For instance, suppose that unacceptable harmful side effects occur subsequent to a patent buyout. In this case, Kremer and Glennerster (2004) argue that the patent authority may have to engage in a potentially wasteful fight with the innovators to recover the buyout money. In contrast to patent buyouts, a sponsor participating in an APC could relatively easily suspend the purchase of a drug or vaccine as soon as unacceptable harmful side effects are discovered (Kremer and Glennerster, 2004). For pharmaceutical products such as vaccines that could

7 See also Layne-Farrar and Schmidt (2010) for a thorough analysis of the hold-up problem in the context of complementary patents. 
relatively easily be specified in advance by governmental agencies, an APC is likely to be as effective as patent buyouts in terms of stimulating research into medicines for neglected diseases (Kremer, 2001). APCs are, however, likely to be politically more attractive than patent buyouts because payments are spread out over a large number of doses and at the same time less vulnerable to collusive behaviour (Maurer, 2005).

From their comparison of the mandatory prize mechanism (applied in the Medical Innovation Prize Act) and APCs, Love and Hubbard (2007) conclude that APCs require a huge degree of ex ante specification before financial support is provided, whereas the prize fund model offers flexibility by linking the reward solely to an ex post assessment of health results for the patients. Additionally, the evaluation of therapeutic benefits after the development of a therapy stimulated by optional reward systems, such as the HIF, may be less difficult than the specification of pharmacological characteristics beforehand, as is required in APCs (Kremer and Glennerster, 2004). Nevertheless, Hollis and Pogge (2008: 7) point out that the HIF is a comprehensive approach applying to 'all kinds of pharmaceutical products that improve human health and not just a particular specified vaccine for a neglected disease'. By linking rewards to actual health benefits rather than 'subsidising sales', the HIF system fosters innovation and improves accessibility in a comprehensive way to improve global health. Kremer and Williams (2010) appear to be generally open-minded towards the prize mechanisms, but they favour a voluntary mechanism, such as the HIF, as opposed to Love and Hubbard's mandatory approach. They argue that the implementation of a mandatory prize fund mechanism could reduce the pharmaceutical industry's expected return on investment, as no adequate alternative incentive mechanism to reward R\&D would substitute for this mechanism if it failed (Kremer and Williams, 2010). Experimenting with voluntary mechanisms would lower this risk. It therefore seems advisable to first experiment with voluntary mechanisms in order to learn more about the most effective designs and also, arguably, to draw conclusions on the effective designs for mandatory mechanisms.

\section{Conclusion and policy recommendations}

Empirical evidence suggests that the incentives from patents in the developing world are not sufficient to promote research into neglected infectious diseases that is adequate to the social and economic costs of those diseases. We have, therefore, analysed several push and pull incentive mechanisms proposed in the literature with respect to the question of whether they mitigate the problem of underinvestment in R\&D for neglected infectious diseases.

Push mechanisms, such as research grants and publicly financed research institutions, appear to be more suitable than pull mechanisms, such as APCs, to promote basic research. Absent any subsidisation of research inputs, private 
incentives to invest in basic research are sub-optimal because basic innovations may be neither patentable nor commercially exploitable. The results of basic research are typically not specifiable in advance so that basic research usually cannot be stimulated through an APC (Kremer and Glennerster, 2004). Nevertheless, basic research discoveries provide the basis for subsequent applied research that is patentable and commercially exploitable (Maurer, 2005). Push mechanisms are, however, vulnerable to moral hazard and adverse selection problems, due to information asymmetries between researchers and research administrators (Webber and Kremer, 2001).

As to prize fund mechanisms, a voluntary mechanism is preferable to the more radical mandatory approach. We recommend experimentation with voluntary mechanisms that focus on a specific product, for example X Prizes, which could then be improved and applied to a broader range of settings if they succeed. Experimentation and trial and error with voluntary mechanisms may also help to refine proposals for mandatory programmes such as the Medical Innovation Prize Fund. Regarding patent buyouts, the buyout price would typically be at least twice as large as the private value of the patent and thus potentially increases R\&D incentives (Kremer, 1998). Purchased patents would typically be placed in the public domain so that an innovation could be produced and marketed at a competitive price. This would mitigate the problem of access to affordable medicines that arises when manufacturers of pharmaceuticals charge monopoly prices.

Legally binding and enforceable APCs are also likely to promote pharmaceutical research into neglected infectious diseases through a transparent, market-oriented approach (Kremer, 2002). Sponsors involved in an APC would typically provide consumers in low-income countries with medicines at zero cost or for modest co-payment. However, APCs appear to be more appropriate than patent buyouts, as they are likely to be at least as effective as patent buyouts in terms of stimulating research but more politically appealing and less vulnerable to collusive behaviour (Kremer and Glennerster, 2004).

Hence, a combination of push and pull programmes appears to be an appropriate strategy for stimulating research into neglected infectious diseases. On the one hand, early-stage (basic) research should be supported through push mechanisms, for example, research grants or publicly financed research institutions. On the other hand, pull mechanisms, such as legally binding and enforceable purchase commitments or prize fund mechanisms, have the potential to stimulate specific, product-oriented research into neglected infectious diseases.

Although the push and pull mechanisms analysed above may successfully address the market failure of the drug development paradigm, public health policy failures still pose a significant barrier to the reduction of the disease burden in developing countries. Especially weak health systems, driven by a low general level of education, financial and physical inaccessibility of pharmaceuticals 
and weak information systems, often prevent already existing drugs from being used or used in an appropriate way in developing countries (Travis et al., 2004). A lack of education, on the one hand, leads to a shortfall in the health workforce, with inexperienced and low-skilled staff working in hospitals and health institutions. On the other hand, improved educational standards may reduce the disease burden by enabling people to use existing health services more effectively and improve the overall hygiene awareness (WHO, 1996). Furthermore, certain members of society in poor countries, especially women, children and people from rural areas, often do not have sufficient access to existing drugs (Bhutta et al., 2004), a situation that contributes to what is commonly referred to as 'health inequity'. Other policy failures directly hinder the development of drugs for neglected diseases and affordable access to medicines in poor countries. Particularly, the international harmonisation of drug development regulations, excessive patent protection and parallel trade legislation are potential barriers to the availability of drugs to treat neglected diseases in developing countries. As a result of the International Conference on Harmonisation, safety regulations on the development and clinical testing of new drugs are not adapted to the benefit-risk preferences of developing countries but are internationally consistent in meeting the needs of developed countries. While basic regulations are necessary to protect consumers' health, excessive regulation might lead to time-consuming and therefore expensive drug development, which can be especially problematic for developing countries, where expected returns are low. This can exclude people in those countries from access to potentially life-saving medicines (Trouiller et al., 2001). In addition, the notion that strengthening patent protection in developing countries, as stipulated in the Agreement on Trade-Related Aspects of Intellectual Property Rights (TRIPS Agreement), stimulates neglected disease research is fiercely debated (Lanjouw, 2003). For instance, Trouiller et al. (2001) argue that with strong patent protection, access to essential drugs in low-income countries could be denied for many years. Finally, the regulation of parallel trade of drugs may also have an impact on the availability of drugs in developing countries. While pharmaceutical companies would typically discriminate prices between countries, and therefore set a lower price in developing countries with a high price elasticity of demand, parallel trade arbitrage will push prices up in those countries, reduce the expected overall profits of drug developers and hence reduce their R\&D incentives (Mueller-Langer, 2012).

To conclude, whereas we focus our analysis on push and pull mechanisms to stimulate the development of drugs for neglected diseases, appropriate R\&D incentive mechanisms alone will not be sufficient to solve the problem of inaccessibility of urgently needed medication in poor countries. Strengthening local health systems and setting an appropriate legal framework will need continued attention in order to reduce the neglected disease burden in the developing world. 


\section{Acknowledgements}

The author thanks Hans-Bernd Schäfer, Martina Samwer, Sebastian Osterrieth, Janis Sussick and Franz Bauhuber for their valuable comments.

\section{References}

Acemoglu, D. and J. Linn (2004), 'Market size in innovation: theory and evidence from the pharmaceutical industry', Quarterly Journal of Economics, 119(3): 1049-1090.

Berndt, E. R., R. Glennerster, M. Kremer, J. Lee, R. Levine, G. Weizsäcker and H. L. Williams (2007), 'Advance market commitments for vaccines against neglected diseases: estimating costs and effectiveness', Health Economics, 16(4): 491-511.

Bhutta, Z. A., I. Gupta, H. de'Silva, D. Manadhar, S. Awasthi, S. M. Hossain and S. A. Salam (2004), 'Maternal and child health: Is South Asia ready for change?', BMJ, 328: $816-819$.

Buckup, S. (2008), 'Global public-private partnerships against neglected diseases: building governance structures for effective outcomes', Health Economics, Policy and Law, 3: 31-50.

DiMasi, J. A., R. W. Hansen and H. G. Grabowski (2003), 'The price of innovation: new estimates of drug development costs', Journal of Health Economics, 22: 151-185.

Food and Drug Administration (FDA) (2011), 'A Review to FDA's Approach to Medical Product Shortages’, FDA Report, 31 October 2011, Silver Spring, MD, USA.

Gallini, N. T. and S. Scotchmer (2002), 'Intellectual Property: When is it the Best Incentive System?', in A. B. Jaffe, J. Lerner and S. Stern (eds), NBER (National Bureau of Economic Research) Innovation Policy and the Economy, vol. 2. Cambridge, MA, USA: MIT Press, 51-77.

Glennerster, R. and M. Kremer (2001), 'A better way to spur medical research and development', Regulation, 23(2): 34-39.

Grabowski, H. G. (2005), 'Increasing R\&D Incentives for Neglected Diseases: Lessons From the Orphan Drug Act', in K. E. Maskus and J. H. Reichman (eds), International Public Goods and Transfer of Technology Under a Globalized Intellectual Property Regime, Cambridge: Cambridge University Press, 457-480.

Grabowski, H. G. and J. M. Vernon (2000), 'The determinants of pharmaceutical research and development expenditures', Journal of Evolutionary Economics, 10(1/2): 201-215.

Hall, B. H. and J. van Reenen (2000), 'How effective are fiscal incentives for R\&D? A review of the evidence', Research Policy, 29: 449-469.

Harhoff, D., F. M. Scherer and K. Vopel (2003), 'Citations, family size, opposition and the value of patent rights', Research Policy, 32(8): 1343-1363.

Hollis, A. (2007), 'Drugs for Neglected Diseases: New Incentives for Innovation', in F. A. Sloan and C. R. Hsieh (eds), Pharmaceutical Innovation: Incentives, Competition, and Cost-Benefit Analysis in International Perspective, Cambridge: Cambridge University Press, 75-90.

Hollis, A. and P. Pogge (2008), The Health Impact Fund: Making New Medicines Accessible for All, New Haven, CT: Incentives for Global Health.

Kettler, H. E. and R. Modi (2001), 'Building research and development capacity for the prevention and cure of neglected diseases: the case of India', Bulletin of the World Health Organization, 79(8): 742-747.

Kremer, M. (1998), 'Patent buyouts: a mechanism for encouraging innovation', Quarterly Journal of Economics, 113(4): 1137-1167. 
Kremer, M. (2001), 'Creating Markets for New Vaccines: Part I: Rationale', in A. B. Jaffe, J. Lerner and S. Stern (eds), NBER Innovation Policy and the Economy, vol. 1. Cambridge, MA, USA: MIT Press, 35-72.

Kremer, M. (2002), 'Pharmaceuticals and the developing world', Journal of Economic Perspectives, 16(4): 67-90.

Kremer, M. and R. Glennerster (2000), 'A world bank vaccine commitment', Brookings Institution Policy Brief, 57: 1-8.

Kremer, M. and R. Glennerster (2004), Strong Medicine, Creating Incentives for Pharmaceutical Research and Neglected Diseases, New Jersey: Princeton University Press.

Kremer, M. and H. Williams (2010), 'Incentivizing Innovation: Adding to the Tool Kit', in J. Lerner and S. Stern (eds), NBER Innovation Policy and the Economy, vol. 10. Chicago, IL, USA: University of Chicago Press, 1-17.

Lanjouw, J. O. (2003), 'Intellectual Property and the Availability of Pharmaceuticals in Poor Countries', in A. B. Jaffe, J. Lerner and S. Stern (eds), NBER Innovation Policy and the Economy, vol. 3. Cambridge, MA, USA: MIT Press, 91-129.

Layne-Farrar, A. and K. M. Schmidt (2010), 'Licensing complementary patents: "patent trolls", market structure, and "excessive royalties"', Berkeley Technology Law Journal, 25: 1121-1144.

Lichtenberg, F. R. and J. Waldfogel (2003), Does Misery Love Company? Evidence From Pharmaceutical Markets Before and After the Orphan Drug Act, NBER Working Paper, No. 9750, Washington, DC: National Bureau of Economic Research.

Liddell, K. (2010), 'The Health Impact Fund: A Critique', in T. Pogge, M. Rimmer and K. Rubenstein (eds), Incentives for Global Public Health: Patent Law and Access to Essential Medicines, Cambridge: Cambridge University Press, 155-180.

Link, M. P., K. Hagerty and H. M. Kantarjian (2012), 'Chemotherapy drug shortages in the United States: genesis and potential solutions', Journal of Clinical Oncology, 30(7): 692-694.

Love, J. and T. Hubbard (2007), 'The big idea: prizes to stimulate R\&D for new medicines', Chicago-Kent Law Review, 82(3): 1519-1554.

Lybecker, K. M. and R. A. Freeman (2007), 'Funding pharmaceutical innovation through direct tax credits', Health Economics, Policy and Law, 2: 267-284.

Maurer, S. M. (2005), The Right Tool(s): Designing Cost-Effective Strategies for Neglected Disease Research, Report to WHO Commission on Intellectual Property Rights, Innovation and Public Health, Geneva: WHO.

Mrazek, M. F. and E. Mossialos (2003), 'Stimulating pharmaceutical research and development for neglected diseases', Health Policy, 64: 75-88.

Mueller-Langer, F. (2012), 'Parallel trade and its ambiguous effects on global welfare', Review of International Economics, 20(1): 177-185.

Pogge, T. (2010), 'The Health Impact Fund: Better Pharmaceutical Innovations at Much Lower Prices', in T. Pogge, M. Rimmer and K. Rubenstein (eds), Incentives for Global Public Health: Patent Law and Access to Essential Medicines, Cambridge: Cambridge University Press, 135-154.

Ricklin, D. and J. D. Lambris (2007), 'Complement-targeted therapeutics', Nature Biology, 25(11): 1265-1275.

Ridley, D. B., H. G. Grabowski and J. L. Moe (2006), 'Developing drugs for developing countries', Health Affairs, 25(2): 313-324.

Rogoyski, R. (2006), 'The orphan drug act and the myth of the exclusivity incentive', The Columbia Science and Technology Law Review, 7(Article 4): 1-22. 
Shulman, S. R. and M. Manocchia (1997), 'The U. S. orphan drug programme: 1983-1995', PharmacoEconomics, 12(3): 312-326.

Singer, P. A. and A. S. Daar (2001), 'Harnessing genomics and biotechnology to improve global health equity', Science, 294: 87-89.

Sonderholm, J. (2009), 'Wild-card patent extensions as a means to incentivize research and development of antibiotics', Journal of Law, Medicine and Ethics, 37(2): 240-246.

Spellberg, B., L. G. Miller, M. N. Kuo, J. Bradley, W. M. Scheld and J. E. Edwards (2007), 'Societal costs versus savings from wild-card patent extension legislation to spur critically needed antibiotic development', Infection, 35(3): 167-174.

Stiglitz, J. E. and A. Jayadev (2010), 'Medicine for tomorrow: some alternative proposals to promote socially beneficial research and development in pharmaceuticals', Journal of Generic Medicines, 7(3): 220-221.

Thorsteinsdóttir, H., T. W. Sáenz, U. Quach, A. S. Daar and P. A. Singer (2004), 'Cuba innovation through synergy', Nature Biotechnology, 22: DC19-DC24.

Travis, P., S. Bennett, A. Haines, T. Pang, Z. Bhutta, A. A. Hyder, N. R. Pielemeier, A. Mills and T. Evans (2004), 'Overcoming health-systems constraints to achieve the Millennium Development Goals', Lancet, 364: 900-906.

Trouiller, P., P. Olliaro, E. Torreele, J. Orbinski, R. Laing and N. Ford (2002), 'Drug development for neglected diseases: a deficient market and a public-health policy failure', Lancet, 359(9324): 2188-2194.

Trouiller, P., E. Torreele, P. Olliaro, N. White, S. Foster, D. Wirth and B. Pécoul (2001), 'Drugs for neglected diseases: a failure of the market and a public health failure?', Tropical Medicine and International Health, 6(11): 945-951.

Villa, S., A. Compagni and M. R. Reich (2009), 'Orphan drug legislation: lessons for neglected tropical diseases', International Journal of Health Planning and Management, 24(1): $27-42$.

Webber, D. and M. Kremer (2001), 'Perspectives on stimulating industrial research and development for neglected infectious diseases', Bulletin of the World Health Organization, 79(8): 735-741.

WHO (World Health Organization) (1996), Investing in Health Research and Development, Report of the Ad Hoc Committee on Health Research Relating to Future Intervention Options, Geneva: World Health Organization.

WHO (2001), World Health Report 2001, Geneva: World Health Organization.

WHO (2005), World Malaria Report 2005, Geneva: World Health Organization.

WHO (2008), The Global Burden of Disease: 2004 Update, Geneva: World Health Organization. 